\title{
Sequence redundancy, rating dimensions, and the exposure effect ${ }^{*}$
}

\author{
ROBERT V. KAIL, JR. \\ University of Michigan, Ann Arbor, Michigan 48104 \\ and \\ HARVEY R. FREEMAN \\ Ohio Wesleyan University, Delaware, Ohio 43015
}

\begin{abstract}
Two experiments investigated Zajonc's (1968) hypothesis that mere repeated exposure to stimuli is a sufficient condition to enhance individuals' attitudes toward those stimuli. In the first experiment, no significant differences in preference were obtained following exposure to high- and low-redundancy sequences of nonsense syllables. In the second study, the effects of repeated exposure were measured along several rating dimensions, revealing significant differences between dimensions. These results were discussed in terms of the limiting conditions of the exposure effect.
\end{abstract}

Recently, Zajonc (1968) has presented evidence which indicates that mere repeated exposure of a stimulus to an individual is a sufficient condition to enhance the individual's attitude toward that stimulus. Subsequent experiments (e.g., Zajonc, Shaver, Tavis, \& van Krevald, 1972; Zajonc, Swap, Harrison, \& Roberts, 1971) which have attempted to determine the limiting conditions of the exposure effect have obtained this positive exposure-affect relationship with a variety of stimuli, exposure frequencies, and experimental conditions. Conversely, Berlyne (1970) found that Ss exposed to a highly redundant exposure sequence preferred novel stimuili to more familiar stimuli. Because Berlyne's (1970) procedure typically involved rating the stimuli during the exposure sequence rather than after, Harrison and Crandall (1972) compared the effects of highly heterogeneous and homogeneous exposure sequences on postexposure ratings of stimuli and found a strong positive relationship between exposure and affect for both sequences.

In addition to using postexposure ratings, the Harrison-Crandall study also used complex Chinese characters as stimuli rather than the simple geometric figures used by Berlyne (1970). Because previous research (e.g., Saegert \& Jellison, 1970) has found the degree of stimulus complexity to interact with the effects of exposure, it is difficult to determine the extent to which the positive relationship found by Harrison and Crandall (1972) was due to postexposure ratings rather than to stimulus complexity. Experiment I further investigated the relationships between redundancy of the exposure sequence, stimulus complexity, and preference. Ss viewed 31 slides consisting of five different nonsense syllables shown at

\footnotetext{
*Experiment I was conducted while the first author was at Ohio Wesleyan University; Experiment II was conducted at the University of Michigan while the first author was a predoctoral trainee on NIMH Grant 5 TO1 MH-06667-14. Thanks to Robert B. Zajonc and Harry P. Bahrick for their critical readings of drafts of this paper.
}

five different frequencies. The stimuli were presented in either a massed (all exposures to each stimulus presented before a new syllable was shown) or spaced (syllables presented randomly) order.

\section{EXPERIMENT I}

Method

\section{Subjects}

The Ss were 94 undergraduates enrolled in introductory psychology courses at Ohio Wesleyan University, who participated in the experiment to satisfy a course requirement. Ss were alternately assigned to the massed or spaced exposure groups.

Stimuli

The stimuli were nonsense syllables of $33 \%$ association value (Glaze, 1928). Ten syllables of intermediate preference in pilot testing were used. Five syllables were assigned randomly to the exposure sequences, while five others served as nonexposed filler stimuli.

\section{Procedure}

Ss were run one at a time and were instructed to merely observe the syllables as they were presented. The syllables were projected onto a blank wall with a Kodak carousel projector for $2 \mathrm{sec}$ each, with the interstimulus interval the fraction of a second required to advance the projector. The total number of exposures was 31 , with individual frequencies of $1,2,4,8,16$. Exposure frequency of each syllable was randomiy determined for each S. Ss in the massed exposure condition viewed all exposures of a nonsense syllable before seeing a new syllable. Thus, a $S$ in the massed exposure condition viewed the " 16 " syllable 16 times consecutively prior to seeing a new syllable. In the spaced exposure condition, the order of the 31 slides was randomly determined for each $S$. After presentation of the slides, Ss rated all 10 nonsense syllables on 7-point scales ranging from very unappealing to very appealing.

\section{Results}

The mean preference ratings as a function of frequency of exposure are presented for both exposure 


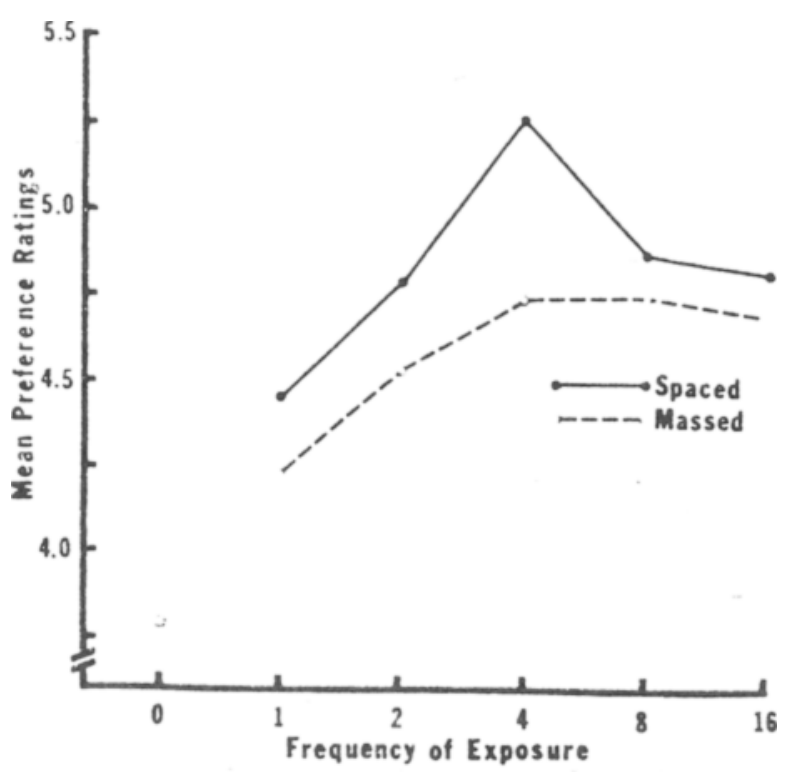

Fig. 1. Mean preference ratings of nonsense syllables as a function of frequency of exposure for massed and spaced exposure sequences.

groups in Fig. 1. Scores range from 1 to 7 , with higher scores indicating greater preference. It is evident that a frequency effect obtained $[\mathrm{F}(4,368)=2.64, \mathrm{p}<.05]$ and that the difference between spaced and massed exposures, though insignificant $[F(1,92)=2.05]$, was in the expected direction. Newman-Keuls tests on differences between the means, collapsed over exposure groups, indicated that syllables exposed 16,8,4 times were preferred significantly more than syllables exposed only once $(\mathrm{ps}<.05)$. There were no other significant differences. The linear trend (Hays, 1963) accounted for $41 \%$ of the variance and was marginally significant $[F(1,465)=3.70, \quad \mathrm{p}<.10]$, while the quadratic component accounted for $49 \%$ of the variance and attained significance $[F(1,465)=4.48, \quad p<.05]$. Collapsing over frequency of exposure and exposure group, the mean of the exposed stimuli was 4.73 compared to 3.79 for the unexposed stimuli, a highly significant difference $[F(1,93)=57.16, p<.001]$.

These findings generally confirm those of Zajonc (1968) and Harrison and Crandall (1972), while further clarifying Berlyne's (1970) results. As in the Harrison-Crandall experiment, a strong positive relationship between exposure and preference obtained. Syllables shown in the spaced exposure sequence were consistently preferred to those exposed in massed orders, as Berlyne's (1970) findings would predict. Thus, when either simple or complex stimuli are presented in low- or high-redundancy exposure sequences, the exposure effect obtains if postexposure ratings are used. High redundancy of exposure seems to impair the effects of exposure, but there is no evidence for a decline in preference at high frequencies of exposure.

\section{EXPERIMENT II}

An unexpected outcome of Experiment I was the significant quadratic trend in the data in contrast to Zajonc's (1968) strong linear relationship between frequency of exposure and preference. The use of simple stimuli rather than the complex stimuli Zajonc used previously may be in part responsible, but Saegert and Jellison's (1970) findings suggest that this effect should appear as a strong decline at the highest exposure frequency. An alternative explanation involves the rating dimensions used in Experiment I, APPEALING/UNAPPEALING. In previous exposure research, several different rating scales have been used to measure the affective charge of the exposed stimuli. These have included GOOD/BAD (Zajonc, 1968), I N T E R E S T I N G / U N I N T E R E S T ING, PLEASING/DISPLEASING, AGREABLE/ DÉSAGRÉABLE (Berlyne, 1970), LIKE/DISLIKE ( $\mathrm{Zaj}$ anc et al, 1972 ), as well as APPEALING/UNAPPEALING. The inherent assumption has been that the exposure phenomenon is generally robust and that different rating dimensions that are presumably correlated all similarly measure this generalized affective change. However, the results of Saegert and Jellison (1970) and Cottrell, Fryrear, and Dorfman (1971) suggest that evaluative and preference ratings may not similarly measure this change. Both sets of experiments indicated an interaction between frequency of exposure and rating dimensions, with exposure producing a linear function for goodness but an inverted U-shaped function for preference. In addition, Harrison (1968) found an inverse relationship between exploratory behavior and liking, suggesting that scales which would tap these variables might yield different exposure functions.

Experiment II was designed to compare systematically the effects of exposure along several rating dimensions. Frequency of exposure and rating dimension were manipulated as within-S variables, with individual Ss rating each stimulus on four separate scales. The exposure sequence was taken from a study by Zajonc, Crandall, Kail, and Swap ${ }^{1}$, in which the positive ratings of stimuli were obtained on a GOOD/BAD scale following $0,1,9,27,243$ exposures.

Four 7-point scales were chosen for use in Experiment II: STABLE/CHANGEABLE, BENEFICIAL/HARMFUL, ATTRACTING/REPELLING, and INTERESTING/BORING. According to the response competition explanation of the exposure effect (Harrison, 1968; Matlin, 1970, 1971), novel stimuli elicit a variety of competing responses which produce a state of tension in the individual. Exposure resolves this response competition by associating a single response to the stimulus and, consequently, exposure is reinforcing. It was predicted that STABLE/CHANGEABLE ratings would become more stable with exposure, as a single 
response is associated with the stimulus; BENEFICIAL/HARMFUL ratings would become more beneficial with exposure as response competition is dissipated. It was predicted that the A T T R A C T I N G/REPELLING a n d INTERESTING/BORING scales would measure the exploratory response elicited by the stimuli and, thus, would decrease with exposure (Harrison, 1968).

\section{Method}

\section{Subjects}

The Ss were 20 undergraduate women from introductory psychology classes at the University of Michigan, who fulfilled a course requirement by their participation in the experiment. Individuals who had participated in this series of experiments or who had any knowledge of Oriental characters were excluded from this experiment. Ss were tested in groups of two to five.

\section{Stimuli}

Pictures of five Chinese characters (from Zajonc, 1968) were shown on 16-mm film. Each exposure consisted of four frames of the same character, about $1 / 6 \mathrm{sec}$ at the projection speed of 24 frames/sec. The total number of exposures was 280 , with individual frequencies of $0,1,9,27,243$. Each stimulus appeared at one frequency only. The interval between exposures was 64 frames (approximately 2-5/6 sec) and appeared as darkness between the exposed characters.

\section{Procedure}

Ss were instructed that they were to observe the series of characters that would be presented to them, then the film was shown. When the film ended, Ss were told that the characters were adjectives in an Oriental language and that they were to guess their meaning along several dimensions. During ratings, slides of the individual characters were shown for $5 \mathrm{sec}$ each using a Nikkormat projector, with order of presentation random for each group of Ss. Each $S$ then rated each stimulus along the four rating dimensions. To partially counterbalance for orientation of the scale, two scales arbitrarily chosen from the four were presented in a positive/negative orientation, while the other two were presented in a negative/positive orientation. Each scale was on a separate page and the pages were assembled randomly to form a test booklet for each $\mathrm{S}$.

\section{Results}

The mean ratings along each rating dimension are presented as a function of frequency of exposure in Fig. 2 with the GOOD/BAD data obtained in the Zajonc, Crandall, Kail, and Swap study. Scores range from 1 to 7 and, in each case, higher scores represent the positive end of the rating scale (i.e., BENEFICIAL, INTERESTING, STABLE, ATTRACTING). ${ }^{2}$ Analysis of variance on these data revealed no significant frequency effect, but there were significant differences between scales $[F(3,57)=28.97, \mathrm{p}<.001]$, as well as the expected significant Scale by Frequency interaction $[F(12,228)=8.01, p<.001]$. Simple effects tests indicated that the predicted negative frequency effect obtained for the INTERESTING/BORING dimension $[F(4,228)=8.85, p<.001]:$ a positive frequency effect

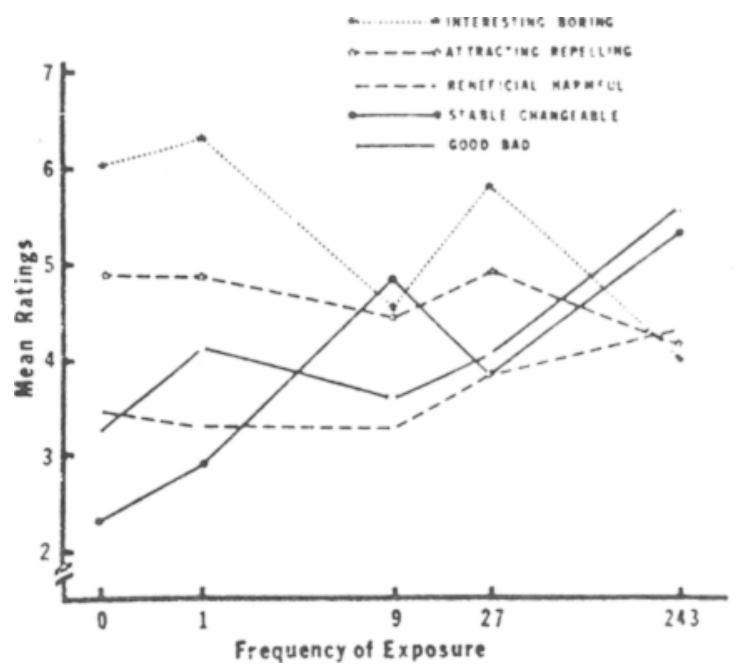

Fig. 2. Mean ratings of Chinese characters on five different rating dimensions as a function of frequency of exposure.

occurred on the STABLE/CHANGEABLE scale $[F(4,228)=13.54, p<.001]$, while no clear effects were present on the two other scales. For both of the significant scales, trend analyses (Hays, 1963) revealed significant linear and quartic components, although the linear components accounted for most of the variance [INTERESTING/BORING: linear, $F(1,228)=18.16$, $\mathrm{p}<.001,51 \%$ of the variance; quartic, $\mathrm{F}(1,228)=15.24, \mathrm{p}<.001,43 \%$ of the variance; ST ABLE/CHANGEABLE: linear, $F(1,228)=41.46$, $\mathrm{p}<.001,77 \%$ of the variance; quartic, $F(1,228)=11.30, p<.005,21 \%$ of the variance $]$.

Further evidence for the differences among rating dimensions was provided by the correlation coefficients computed between all pairs of the rating scales. These correlations are presented in Table 1. Three of the four significant correlations were in the predicted direction; that is, exploratory and evaluative scales correlated positively with themselves but negatively with each other. The single correlation not in the expected direction was between the BENEFICIAL/HARMFUL and ATTRACTING/REPELLING scales, neither of which produced a significant exposure effect, and accounted for only $7 \%$ and $4 \%$ of the variance, respectively, associated with differences between rating scales.

\section{DISCUSSION}

Experiment I demonstrated that high-redundancy exposure sequences consisting of simple stimuli can lead to an impaired exposure effect, but there was no evidence of a decline in preference as a function of exposure. Experiment II investigated possible differences in rating scales as a cause of an unexpected strong quadratic component in Experiment I and found that a simple dichotomy can be made between scales that 
Table 1

Correlations Between Four Rating Dimensions Used in Experiment II

\begin{tabular}{|c|c|c|c|c|}
\hline & \multicolumn{2}{|c|}{ Evaluative Dimensions } & \multicolumn{2}{|c|}{ Exploratory Dimensions } \\
\hline & $\begin{array}{c}\text { STABLE/ } \\
\text { CHANGEABLE }\end{array}$ & $\begin{array}{l}\text { BENEFICIAL/ } \\
\text { HARMFUL }\end{array}$ & $\begin{array}{l}\text { ATTRACTING/ } \\
\text { REPELLING }\end{array}$ & $\begin{array}{l}\text { INTERESTING/ } \\
\text { BORING }\end{array}$ \\
\hline \multicolumn{5}{|l|}{ Evaluative Dimensions } \\
\hline STABLE/CHANGEABLE & -- & $.34^{*}$ & .11 & $-.41^{*}$ \\
\hline BENEFICIAL/HARMFUL & $.34 *$ & -2 & $.51^{*}$ & -.17 \\
\hline \multicolumn{5}{|l|}{ Exploratory Dimensions } \\
\hline ATTRACTING/REPELLING & .11 & $.51^{*}$ & -- & $.60^{*}$ \\
\hline INTERESTING/BORING & $-.41^{*}$ & -.17 & $.60^{*}$ & -- \\
\hline
\end{tabular}

${ }^{*} p<.001$

measure exploratory vs affective or evaluative responses to stimuli. Both experiments suggest further limiting conditions to the attitudinal effects of mere exposure.

According to Berlyne's (1970) two-factor theory, the hedonic value of stimuli first increases due to habituation, then declines due to boredom. Because simple stimuli habituate more rapidly than complex stimuli, preference for simple stimuli frequently is an inverted U-shaped function of exposure frequency. The results of Experiment I are entirely consistent with the two-factor theory. Exposure resulted in an increased preference that quickly asymptoted, presumably as Ss became habituated to the stimuli. Further, Ss in the massed condition habituated at a lower preference level than those in the spaced condition, as the two-factor theory would predict. Finally, the significant quadratic component in the data suggests that further exposure would have resulted in decreased preference as boredom increased.

From Experiment II, it is clear that investigators must be cautious in their selection of a rating scale with which to measure the effects of mere exposure. Scales such as INTERESTING/BORING may reflect a short-term, situational, or exploratory response to stimuli, while GOOD/BAD, STABLE/CHANGEABLE seem to measure the longer term effects of evaluation, affiliation, or liking. A third group of scales, including A T T R A C T I N G/RE P E L L I N G a n d BENEFICIAL/HARMFUL are ambiguous to individuals or imply different psychological dimensions to different Ss and, thus, produce no consistent data following exposure.

Moreover, it is clear that when Ss are to respond to stimuli along several different dimensions following exposure, they apparently can discern separate appropriate responses to each stimulus. How Ss respond when they are not given multiple response dimensions is less clear. Crandall, Harrison, and Zajonc ${ }^{3}$ presented Ss with a highly redundant exposure sequence, then took ratings of the stimuli either immediately after the exposure sequence or after delays of 1 or 4 weeks. Ss responded more favorably to the novel stimuli only with immediate ratings, but in both delay conditions the familiar stimuli were again preferred. Apparently, if the general experimental task is boring or tedious, Ss may reflect this boredom in their ratings of the most frequently seen stimuli, but. when such situational boredom is allowed to dissipate, the positive exposure-affect relationship reappears. The Crandall, Harrison, and Zajonc study suggests that, if Ss do not have the opportunity to make multiple responses to stimuli, they may make the dominant response, regardless of its appropriateness to the available rating dimension.

In conclusion, these results provide additional support for the exposure effect. Using simple stimuli in a brief exposure sequence and complex stimuli in an extended sequence, repeated exposure to a stimulus enhanced individuals' attitudes toward those stimuli. However, these responses are now seen as sensitive to procedural manipulations, and small changes in these procedures can actually reverse the effect.

\section{REFERENCES}

Berlyne, D. E. Novelty, complexity, and hedonic value. Perception \& Psychophysics, 1970, 8, 279-286.

Cottrell, N. B., Fryrear, R. L., \& Dorfman, D. D. An information theory approach to the relationship between frequency of exposure of novel stimuli and their hedonic value. Paper presented at the Midwest Psychological Association meeting, Detroit, Michigan, 1971.

Glaze, J. A. The association value of nonsense syllables. Journal of Genetic Psychology, 1928, 35, 225-269.

Harrison, A. A. Response competition, frequency, exploratory behavior, and liking. Journal of Personality \& Social Psychology, 1968, 9, 363-368.

Harrison, A. A., \& Crandall, R. Heterogeneity-homogeneity of exposure sequence and the attitudinal effects of exposure. Journal of Personality \& Social Psychology, 1972. 21, 234-238.

Hays, W. L. Statistics for psychologists. New York: Holt, Rinehart, \& Winston, 1963.

Matlin. M. Response competition as a mediating factor in the frequency-affect relationship. Journal of Personality \& Social Psychology, 1970. 17, 536-552.

Matlin, M. Response competition, recognition, and affect. Journal of Personality \& Social Psychology, 1971, 19, 295-300.

Saegert, S. C., \& Jellison, J. M. Effects of initial level of response competition and frequency of exposure on liking and exploratory behavior. Journal of Personality \& Social Psychology, 1970, 16, 553-558.

Zajonc, R. B. Attitudinal effects of mere exposure. Journal of Personality \& Social Psychology Monograph Supplement. 1968. 9(2. Pt. 2). 1-27.

Zajonc, R. B.. Shaver. P., Tavris. C.. \& van Krevald. D. Exposure. satiation. and stimulus discriminability. Journal of Personality \& Social Psychology. 1972, 21, 270-280. 
Zajonc, R. B.. Swap, W. C., Harrison, A. A., \& Roberts. P. Limiting conditions of the exposure effect: Satiation and relativity. Journal of Personality \& Social Psychology, 1971, 18, 384-391.

\section{NOTES}

1. Zajonc, R. B., Crandall, R., Kail, R. V., Jr., \& Swap, W. C. Unpublished study entitled "The effect of extreme exposure frequencies on different affective ratings of stimuli," under editorial consideration, 1972.
2. Due to an error in the preparation of the scales, the BENEFICIAL/HARMFUL scale was only a 6-point scale; thus it is scored from 1 to 6 .

3. Crandall, R., Harrison, A. A., \& Zajone, R. B. Unpublished study entitled "The permanence of the positive and negative effects of stimulus exposure: A 'sleeper effect'?" under editorial consideration, 1972.

(Received for publication April 16, 1973; accepted May 9, 1973.) 